\begin{tabular}{|c|c|}
\hline TABLE 2 & $\begin{array}{l}\text { Members of the National Rhinitis } \\
\text { Task Force }\end{array}$ \\
\hline
\end{tabular}

Thomas Casale, M.D., Papillion, Nebraska

Mark Dykewicz, M.D., St. Louis, Missouri

Stanley Fineman, M.D., Marietta, Georgia

Clifton Furukawa, M.D., Seattle, Washington

David Golden, M.D., Owings Mills, Maryland

Gary Gross, M.D., Dallas, Texas

Michael Kaliner, M.D., Washington, D.C.

Dennis Ledford, M.D., Tampa, Florida

Phil Lieberman, M.D., Cordova, Tennessee

James Mallette, M.D., Florence, Alabama

Don Mitchel1, M.D., Jackson, Mississippi

Robert Reisman, M.D., Williamsville, New York

Richard Rosenthal, M.D., Great Falls, Virginia

Russell Settipane, M.D., Providence, Rhode Island

Sheldon Spector, M.D., Los Angeles, California

Michael Springer, M.D., Knoxville, Tennessee

William Storms, M.D., Colorado Springs, Colorado

Bruce Wolff, M.D., Nashville, Tennessee

\begin{tabular}{l|c|c}
\hline TABLE 3 & $\begin{array}{l}\text { Incidence of Allergic versus } \\
\text { Nonallergic Rhinitis }\end{array}$ \\
\hline Pure allergic & $\mathrm{n}=419$ & $43 \%$ \\
\hline Pure nonallergic & $\mathrm{n}=224$ & $23 \%$ \\
\hline Mixed & $\mathrm{n}=332$ & $34 \%$ \\
\hline Total & $\mathrm{n}=975$ & $100 \%$ \\
\hline
\end{tabular}

charts at the offices of 18 allergists (see Table 2, above) across the United States.

Reviewers first sought to categorize patients into two groups, "pure allergic" and "pure nonallergic." Pure allergic patients had to exhibit symptoms upon exposure to an allergen and react positively to a skin test and the patient's history had to show no infection, physical or structural defects, or environmental factors that might cause rhinitis. Of 975 patient charts reviewed, 43\% were identified as having pure allergic thinitis.

To belong to the "pure nonallergic" category, patients had to exhibit chronic, rather than seasonal, symptoms and skin test results had to be negative. Patient history often revealed nonallergic components, such as nasal polyps, tumors, deviated septa, infection, hormone use, medication use, or environmental exposures. Fewer than $25 \%$ of the patients whose charts were reviewed were identified as having pure nonallergic rhinitis (see Table 3, above)

Reviewers then looked at patients in the survey population who showed symptoms of both allergic and nonallergic rhinitis. They constituted $34 \%$ of the population. When these were combined with the pure nonallergic group, more than half $(57 \%)$ of rhinitis patients surveyed have a nonallergic component to their rhinitis. Applying these ratios to the population of 62 million Americans who suffer from rhinitis, 27 million people would have purely allergic rhinitis and 35 million people would have nonallergic or mixed.

The results of the task force survey thus suggest that the majority of patients require treatment that addresses either nonallergic or mixed symptoms. (It is important to remember that the survey was done using charts of patients who had consulted allergy specialists-patients who had already been diagnosed as having "allergy.")

Because the data in this document is conservative, the figures for the nonallergic/mixed combined category are likely to be even higher if charts for family-practice patients were also analyzed. A current survey evaluating the nonallergic components of rhinitis is incorporating primary care data to more accurately assess the impact of nonallergic and mixed rhinitis.

\section{Treatment Choices}

The true cause of rhinitis symptoms is often not identified because allergy skin tests are rarely part of routine office visits and patients are often unable to describe their triggers completely and correctly. Referrals to allergy specialists usually are made only after repeated failures of other treatments.

Physicians can (and do) recommend that patients avoid triggers, but avoidance only works if the triggers can be clearly identified and eliminated. A pharmacologic solution should be a safe, easy-to-use medication indicated for both allergic and nonallergic rhinitis symptoms, but current medications do not often meet all these objectives. Ineffective treatment options and unsuccessful outcomes can be frustrating to both patient and physician. Table 4 on page 7 lists some products commonly prescribed for rhinitis.

\section{Mast Cell Stabilizers}

Cromolyn sodium, an over-the-counter medication originally designed to treat asthma, has been prescribed for rhinitis for decades. Cromolyn sodium inhibits the degranulation of sensitive mast cells, thus inhibiting the release of mediators of allergic response and inflammation. Physicians use it often, especially for pregnant women and children. While it is very safe, has few side effects, and does address both early and late amylic phase reactions, it is not very effective, especially for patients who have acule symptoms. ${ }^{13}$

For optimal benefit, cromolyn sodium must be taken before exposure to an allergen and the nasal passages must be patent, which may require an additional prescription for a nasal decongestant. Acute symptoms treated with cromolyn sodium may require the addition of an antihistamine-decongestant combination. The product must be used throughout the allergy season. There is no evidence that cromolyn sodium is an effective treatment for vasomotor thinitis. ${ }^{13,14}$ 


\section{Anticholinergics}

Ipratropium bromide, another safe medication with few side effects, is useful in treating rhinorrhea but will not address allergic symptoms. Ipratropium bromide is a quaternary amine that minimally crosses the nasal and gastrointestinal membrane, reducing systemic anticholinergic effects. ${ }^{15,16}$ Although it can be combined with nasal steroids to treat rhinitis, ipratropium bromide is not very effective for vasomotor rhinitis.

\section{Decongestants}

Topical decongestants like pseudoephedrine are systemic medications that may alleviate nasal congestion. However, they may have adverse effects, such as loss of appetite, anxiety, nervousness, and insomnia. Patients who have an arrhythmia, angina, hypertension, or hyperthyroidism are not good candidates for these medications because they can aggravate these conditions. The Food and Drug Administration (FDA) recently issued a recall for all products containing phenylpropanolamine (PPA) due to safety concerns.

Topical decongestants like oxymetazoline can be effective in treating rhinitis-induced congestion but only for fewer than four days. Longer use may lead to rhinitis medicamentosa or "rebound" congestion. ${ }^{17}$

\section{Intranasal Corticosteroids}

Beclomethasone dipropionate, budesonide, and flucticasone are all nasal corticosteroids that have been approved for treatment of seasonal allergic thinitis and perennial nonallergic thinitis. Their localized anti-inflammatory activity and minimal systemic absorption make them very effective. Side effects include nasal irritation and nasal bleeding. Because they are steroids, there is some concern about growth suppression in children. Current FDA guidelines require that children younger than 12 who receive either nasal or inhaled steroids be measured regularly using a stadiometer. ${ }^{18}$

\section{Antihistamines}

Antihistamine options include either first- or second-generation oral antihistamines and a nasal antihistamine. Because first-generation oral antihistamines, such as diphenhydramine and hydroxyzine, are considered strong sedatives, they are usually not first-line choices for most patients. Loratadine and fexofenadine, both second-generation oral antihistamines, are effective in reducing sneezing, itching, and rhinorrhea, but they have minimal effects on nasal congestion and postnasal drip. Therefore, they may be prescribed in combination with other medications. ${ }^{+}$

Like second-generation oral antihistamines, the nasal antihistamine azelastine has an onset of action within three hours. It is the only second-generation antihistamine to be approved to treat seasonal allergic rhinitis in adults and children age 5 and over, as well as nonallergic vasomotor rhinitis in adults and children age 12 and over. It is effective in treating the symptoms of rhinitis, including

\begin{tabular}{|c|c|c|}
\hline & $\begin{array}{c}\text { Seasonal Allergic } \\
\text { Rhinitis }\end{array}$ & $\begin{array}{l}\text { Nonallergic } \\
\text { Rhinitis }\end{array}$ \\
\hline Claritin & $\checkmark$ & \\
\hline Allegra & $\checkmark$ & \\
\hline Zyrtec & $\checkmark$ & \\
\hline Astelin & $\checkmark$ & $\checkmark$ \\
\hline Beconase AQ & $r$ & $\checkmark$ \\
\hline Flonase & $\checkmark$ & $\checkmark$ \\
\hline Nasacort & $\checkmark$ & \\
\hline Nasonex & $\checkmark$ & \\
\hline Rhinocort & $\checkmark$ & $\checkmark$ \\
\hline Rhinocort AQ & $\checkmark$ & \\
\hline Vancenase $A Q$ & $\checkmark$ & $\checkmark$ \\
\hline \multicolumn{3}{|c|}{$\begin{array}{l}\text { Note: Claritin, Nasonex, and Vancenase are trademarks of Schering-Plough. } \\
\text { Allegra and Nasacort are trademarks of Aventis. Rhinocort is an AstraZeneca } \\
\text { trademark. Beconase and Flonase are trademarks of GlaxoSmithKline and Zyrtec } \\
\text { is a Pfizer trademark. }\end{array}$} \\
\hline
\end{tabular}

\section{TABLE 5 Target Drugs}

Antihistamines - Oral Solids

- Claritin (loratadine)

- Zyrtec (cetirizine)

- Allegra (fexolenadine)

Antihistamines - Nasal Spray

- Astelin (azelastine)

Nasal Steroids

- Nasalide, Nasarel (flunisolide)

- Beconase, Beconase AQ, Beconase AQ DS, Vancenase,

- Vancenase AQ (beclomethasone)

- Nasacort, Nasacort AQ (triamcinolone)

- Rhinocort, Rhinocort AQ (budesonide)

- Flonase (fluticasone)

- Nasonex (mometasone)

nasal congestion and postnasal drip.+19 The most common side effects are bitter taste, headache, somnolence, and nasal burning.

\section{Evaluating Utilization Patterns}

Medication costs for treatment of rhinitis continue to rise, in some cases quite sharply. For example, in 1998, the cost of prescribed 